\title{
The Effect of Sea Tangle Supplementation and Exercise Training on Blood Glucose and Lipid Profile in Rats
}

\author{
Hye-Jin Hwang', Yi-Sub Kwak², Hyang-Suk Kim¹, Yung-Hyun Choi ${ }^{3}$, Byung-Woo Kim4, \\ Hyun-Ju Kwon ${ }^{4}$ and Byung-Kon Yoon ${ }^{5}$ * \\ ${ }^{1}$ Department of Food and Nutrtion, Dong-Eui University, Busan 614-714, Korea \\ ${ }^{2}$ Department of Physical Education, Dong-Eui University, Busan 614-714, Korea \\ ${ }^{3}$ Department of Oriental Medicine, Dong-Eui University, Busan 614-052, Korea \\ ${ }^{4}$ Department of Life Science \& Biotechndogy, Dong-Eui University, Busan 614-714, Korea \\ ${ }^{5}$ Deparment of Special Physical Ecucation, Dong-Eui University, Busan 614714, Korea
}

Received April 14, 2010 /Accepted May 13, 2010

\begin{abstract}
The purpose of this study was to investigate the effect of Sea Tangle supplementation and exercise training on blood glucose and lipid profile in rats. Twenty seven, 4-week old male Sprague-Dawley rats were divided into the control group $(C, n=9)$, sea tangle group $(D, n=9)$ and sea tangle+exercise group $(\mathrm{D}+\mathrm{T}, \mathrm{n}=9)$. Exercise training was performed 5 days a week using a treadmill running program for 6 weeks $(5 \mathrm{~m} / \mathrm{min}, 0 \%$ grade, $30 \mathrm{~min})$. There was no difference in blood glucose (C: $175.9 \pm 47.5$, D: $173.9 \pm 34.0, \mathrm{D}+\mathrm{T}: 165.0 \pm 38.0 \mathrm{mg} / \mathrm{dl}$ ) and triglyceride (C: $251.1 \pm 91.8, \mathrm{D}: 215.0 \pm 90.0, \mathrm{D}+\mathrm{T}: 200.0 \pm 89.3$ $\mathrm{mg} / \mathrm{dl})$ among the groups. Total cholesterol value of the $\mathrm{D}+\mathrm{T}$ group $(81.8 \pm 11.2 \mathrm{mg} / \mathrm{dl})$ was significantly lower than that of the $C(103.0 \pm 13.5 \mathrm{mg} / \mathrm{dl})$ and $\mathrm{D}(102.1 \pm 14.5 \mathrm{mg} / \mathrm{dl})$ groups. High density lipoprotein cholesterol (HDL-C) was significantly high in the $\mathrm{D}+\mathrm{T}(40.9 \pm 9.7 \mathrm{mg} / \mathrm{dl})$ group compared with the $C(32.6 \pm 3.8 \mathrm{mg} / \mathrm{dl})$ group and $\mathrm{D}(31.7 \pm 7.3 \mathrm{mg} / \mathrm{dl})$ group. The value of low density lipoprotein cholesterol (LDL-C) for the D $(98.0 \pm 41.0 \mathrm{mg} / \mathrm{dl})$ group was statistically lower than the C $(114.5 \pm 41.8 \mathrm{mg} / \mathrm{dl})$ group, and higher than the $\mathrm{D}+\mathrm{T}(91.2 \pm 41.7 \mathrm{mg} / \mathrm{dl})$ group. In conclusion, sea tangle injection and exercise had a positive effect on blood lipid profiles.
\end{abstract}

Key words : Sea Tangle, blood glucose, triglyceride, cholesterol, high density lipoprotein, low density lipoprotein

\section{서 론}

최근 우리나라에서도 급격한 경제 성장과 전반적인 생활수 준의 향상으로 식생활이 서구화되고, 가공식품의 섭취가 증가 하는 양상을 보이고 있으며, 이러한 식생활의 변화와 함께, 암, 심장병, 고혈압, 당뇨병 등으로 인한 사망률이 높아지고 있다[6,17]. 특히, 당뇨병은 각종 합병증으로 인하여 국민건강 에 매우 심각한 문제로 대두되고 있다. 당뇨는 혈당조절 능력 의 감소와 고지혈증으로 인한 콜레스테롤의 함양이 증가되는 것이 주 위험인자로 인식되고 있다. 이러한 혈당과 지질의 조 절방법으로 식이섬유의 섭취와 운동이 매우 중요한 역할을 하고 있으며, 예방에 효과적이라는 보고가 대두되고 있다.

인간의 소화 효소에 의해 소화되지 않는 난소화성 다당류의 총체로 정의된 식이섬유는 화학적 성질에 따라 불용성 식이섬 유(insoluble dietary fibers) 와 수용성 식이섬유(soluble dietary fibers)로 나뉘어 진다[22]. 식이 섬유의 특성은 물을 흡수 하는 능력, 양이온 교환 능력, gel형성 능력, 흡착력 등이 있어

*Corresponding author

Tel : +82-51-890-2512, Fax : +82-51-890-2157

E-mail : lobo06@deu.ac.kr
변비의 완화, 혈장 콜레스테롤의 저하, 내당 능력의 개선효과, 유독성 유기물질의 흡수 및 회석효과 등이 있는 것으로 알려 져 있다. 따라서 식이섬유는 심혈관계질환의 예방과 당뇨병의 유병율을 낮추어 주는 생리활성물질로 널리 인식되어 있다 [26]. Trowel [30]은 식이섬유소의 섭취 부족이 당뇨병의 원인 으로 작용할 가능성이 있다고 제시하였으며, Anderson과 Chen [3]도 고섬유소 식이를 섭취하였을 때 당뇨병 환자의 혈당이 감소하므로 인슐린 요구량이 감소한다고 하였다. 또한 식이 섬유소는 장내 콜레스테롤 수준을 저하시키고 심장병 및 대장암의 발병률을 낮춘다고 보고되고 있다[9,22,24].

그 중 다시마(Laminaria japonica)는 식이섬유를 약 32 $75 \%$ 함유하고 있으며, 그 중 51 85\%가 수용성 식이섬유에 해 당된다[19]. 수용성 식이섬유는 불용성 식이섬유에 비해 보수 력이 커서 점도가 높은 gel을 형성하므로 위 내용물의 체류시 간을 연장하고 흡수억제 작용을 함으로써 포도당의 흡수를 저 하시키고 당뇨병 환자의 당내성을 증가 시킬 수 있다[29]. 특히, 다시마에 포함된 fucoidan는 식이섬유로서의 특성과 효능에 대한 연구와 관심이 크게 고조되었다. Fucoidan은 heparin의 대체물질로서 항혈액응고 작용 이외에 항암 및 면역조절 작용 을 가지고 있는 것으로 보고되고 있다[8]. Cho와 Bang [7] 연구 
에서는 다시마의 투여가 당뇨 유발쥐의 혈당 감소에 효과가 있는 것으로 보고하고 있다. 그 외에의 연구들에서도 다시마가 혈당 감소에 긍정적인 효과가 있음을 보여주고 있다 $[5,13,19]$

운동은 지방 대사를 활성화시켜 총 콜레스테롤(total cholesterol), 중성지방(triglyceride), 고밀도 지단백 콜레스테롤 (high density lipoprotein cholesterol) 등의 혈중 지질 성분에 긍정적인 영향을 미치는 것으로 보고되고 있다[2]. 또한 운동 트레이닝에 의하여 혈당량이 개선되었다는 연구가 있다[18].

다시마 투여를 통한 혈당강하와 지질의 향상에 대한 선행 연구들은 당뇨병의 개선에 초점을 맞추고 있으며 운동과 관련 된 다시마의 효과와 예방차원에서의 효능에 관한 연구는 부족 한 실정이다. 따라서 본 연구의 목적은 다시마의 투여와 운동 이 정상인의 혈당량과 지질개선에 어떠한 효과를 미치는지와 다시마와 운동의 병행이 시너지효과를 유발 할 수 있는지에 대한 기초자료를 제공하는데 있다.

\section{재료 및 방법}

\section{실험동물 및 식이섭취}

본 실험은 생후 6주령의 수컷 Sprague Dawley 27마리를 분양받아 고형기초사료로 일정한조건(온도 $22 \pm 2^{\circ} \mathrm{C}$, 습도 4 5 55\%, 명암: 12 시간 light/dark cycle)에서 일주일간 적응시 킨 후, 난괴법에 의하여 대조군(C), 다시마투여군(D)과 다시마 투여+트레드밀 훈련군 $(\mathrm{D}+\mathrm{T})$ 으로 나누었다. 다시마분말은 동 결 건조하여 분말상태로 만들어 식이에 첨가하였으며 첨가량 은 $5 \mathrm{~g} / \mathrm{kg}$ diet로 하였다. 실험식이 구성은 Table 1 과 같이 AIN-76의 식이조성에 의해 조제하였다.

\section{운동방법}

1 주간의 환경 적응기와 1 주간의 트레드밀 훈련기간을 거친

Table 1. Diet composition of experimental diet $(\mathrm{g} / \mathrm{kg}$ diet)

\begin{tabular}{lcc}
\hline Ingredient & $\mathrm{C}$ & $\mathrm{D}, \mathrm{D}+\mathrm{T}$ \\
\hline Casein & 400.0 & 400.0 \\
Cornstarch & 272.4 & 267.4 \\
Dextrinized cornstarch & 132.0 & 132.0 \\
Soybean oil & 70.0 & 70.0 \\
Fiber & 50.0 & 50.0 \\
Mineral mix ${ }^{1)}$ & 35.0 & 35.0 \\
Vitamin mix & 10.0 & 10.0 \\
L-Cystine & 3.0 & 3.0 \\
Choline bitartrate & 2.5 & 2.5 \\
Tert-butylhydroquinone & 0.014 & 0.014 \\
\hline ST supplementation & & 5
\end{tabular}

C: control group, D: Sea Tangle powder supplemented group, D+T: Training and Sea Tangle Powder supplemented group. ${ }^{1)}$ AIN-76 mineral mix.

${ }^{2)}$ AIN-76 vitamin mix.
추 적응 여부를 가려, 6주간의 트레드밀(Pro-Jog EJ36GLE, Korea Hi-Tech) 훈련을 실시하였다. 적응훈련은 1 주간 매일 같은 시간대에 $10 \mathrm{~m} / \mathrm{min}(0 \%$ grade)의 속도로 10 분간 실시하 였으며, 본 훈련은 $15 \mathrm{~m} / \mathrm{min}(0 \%$ grade)로 시작하여 매 주 속도를 $5 \mathrm{~m} / \mathrm{min}$ 씩 증가하여 훈련 마지막 주까지 $30 \mathrm{~m} / \mathrm{min}$ 의 속도를 유지하였다. 본 훈련의 경사도와 훈련 시간은 $0 \%$ 로 30 분간 실시하였다.

\section{채혈 및 분석방법}

본 실험의 채혈은 $\mathrm{D}$ 대학교 식품영양학과 동물실험실에서 시행되었으며, 모든 실험동물은 채혈 12 시간 전 금식시킨 뒤 마취제 에틸에테르를 이용하여 마취시켜 희생하였다. 마취된 실험동물은 해부판에 사지를 고정시키고, $70 \%$ 알코올 분무기 로 복부를 분무한 뒤 3 방향으로 절개한 다음 $10 \mathrm{ml}$ 주사기를 이용하여 복부대동맥에서 약 $10 \mathrm{ml}$ 의 동맥혈을 채혈하였다. 채혈된 혈액은 원심분리기로 혈청을 분리하여, Revoco社 (USA)의 Deepfreezer $\left(-70^{\circ} \mathrm{C}\right.$ 냉동고)에 보관하여 혈액분석기 (DT6011, Johnson \& Johnson, USA) 를 이용하여 혈당, triglyceride, total cholesterol, high density lipoprotein cholesterol (HDL-C)을 분석하였다. Low density lipoprotein-cholesterol (LDL-C)는 Fridewald법에 따라 산출하였다.

\section{자료처리방법}

모든 실험 분석 결과는 SPSS (ver. 17.0)을 이용하여 각 군 의 평균과 표준편차를 계산하였고 일원배치 분산분석(oneway analysis of variance)을 한 후 $a=0.05$ 수준에서 Tukey's post hoc test에 의하여 각 실험군 평균치간의 유의성을 검정 하였다.

\section{결 과}

다시마 투여와 운동에 의한 혈당의 차이를 관찰하고자 측정 한 결과는 Fig. 1 과 같다. 대조군(C)에서의 혈당치는 $175.9 \pm$ $47.5 \mathrm{mg} / \mathrm{dl}$ 이었고, 다시마군(D)은 $173.9 \pm 34.0 \mathrm{mg} / \mathrm{dl}$, 다시마 + 운동군 $(\mathrm{D}+\mathrm{T})$ 에서는 $165 \pm 38.0 \mathrm{mg} / \mathrm{dl}$ 이었다. 그러나 통계적 으로 그룹간의 차이는 나타나지 않았다. Fig. 2는 triglyceride (TG) 농도의 그룹간 차이를 보여주고 있다. C그룹(251.1 \pm 91.8 $\mathrm{mg} / \mathrm{dl})$ 과 비교하여 $\mathrm{D}$ 그룹 $(215 \pm 90.0 \mathrm{mg} / \mathrm{dl})$ 과 $\mathrm{D}+\mathrm{T}$ 그룹 $(200 \pm 89.3 \mathrm{mg} / \mathrm{dl})$ 의 triglyceride수치는 낮은 경향을 보였으나 통계적으로 유의한 차이가 없었다.

총 콜레스테롤(TC) 수치(Fig. 3)는 $\mathrm{D}+\mathrm{T}$ 그룹(81.8 \pm 11.2 $\mathrm{mg} / \mathrm{dl})$ 이 다른 두 그룹(C: $103 \pm 13.5, \mathrm{D}: 102.1 \pm 14.5 \mathrm{mg} / \mathrm{dl})$ 에 비해 통계적으로 유의하게 낮은 수치를 보였다 $(\mathrm{p}<0.05)$. High

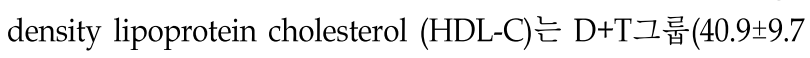
$\mathrm{mg} / \mathrm{dl})$ 에서 다른 두 그룹(C: $32.6 \pm 3.8, \mathrm{D}: 31.7 \pm 7.3 \mathrm{mg} / \mathrm{dl}$ )과 


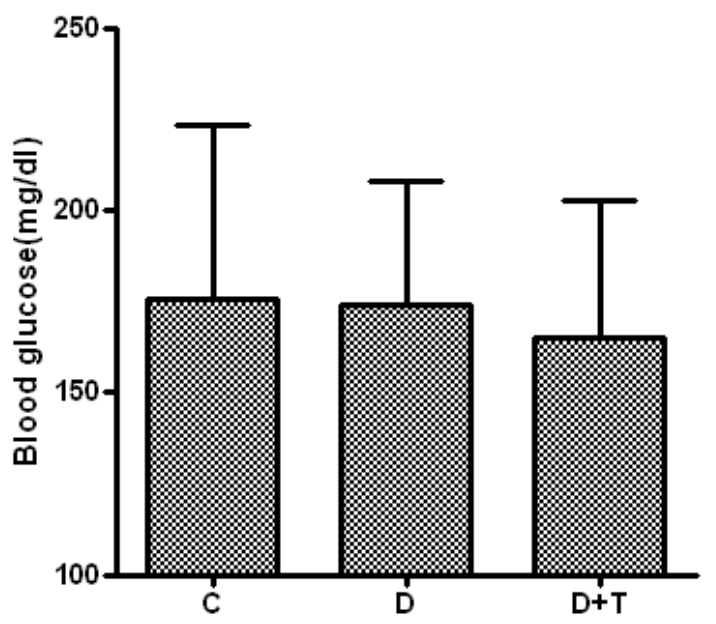

Fig. 1. Comparison of blood glucose among control group, sea tangle supplemented group, and training and sea tangle powder supplemented group. C: control group, D: Sea Tangle powder supplemented group, D+T: Training and Sea Tangle Powder supplemented group.

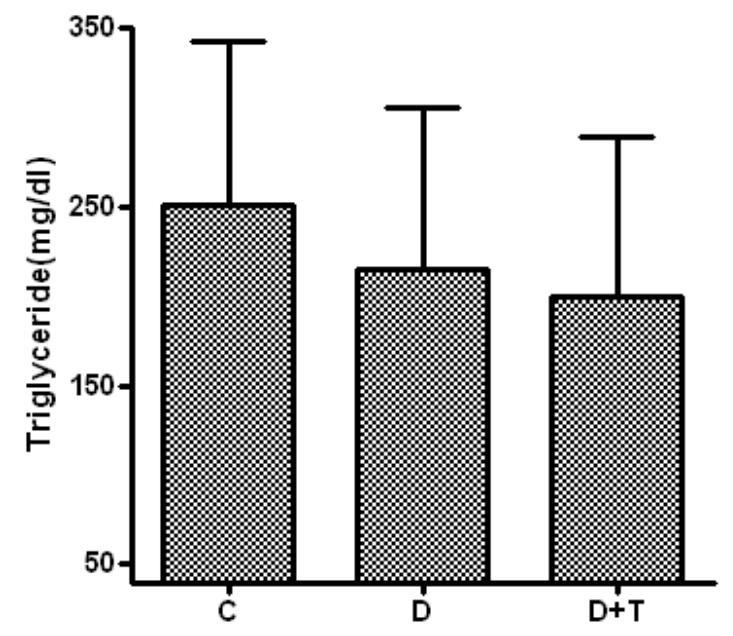

Fig. 2. Comparison of triglyceride among control group, sea tangle supplemented group, and training and sea tangle powder supplemented group. C: control group, D: Sea Tangle powder supplemented group, D+T: Training and Sea Tangle Powder supplemented group.

비교하여 통계적으로 유의하게 높은 수치를 보였다 $(\mathrm{p}<0.05)$ (Fig. 4). Low density lipoprotein-cholesterol (LDL-C)는 C그 룹 $(114.5 \pm 41.8 \mathrm{mg} / \mathrm{dl})$ 에서 가장 높은 수치를 보였으며, $\mathrm{D}$ 그룹 $(98.0 \pm 41.0 \mathrm{mg} / \mathrm{dl})$ 은 C그룹에 비해 유의하게 낮은 수치를 보 였으나 $\mathrm{D}+\mathrm{T}$ 그룹 $(91.2 \pm 41.7 \mathrm{mg} / \mathrm{dl})$ 에 비해 유의하게 높은 수 치를 보였다(Fig. 5).

\section{고 찰}

연구결과 혈당과 $\mathrm{TG}$ 는 그룹 간 유의한 차이가 존재하지

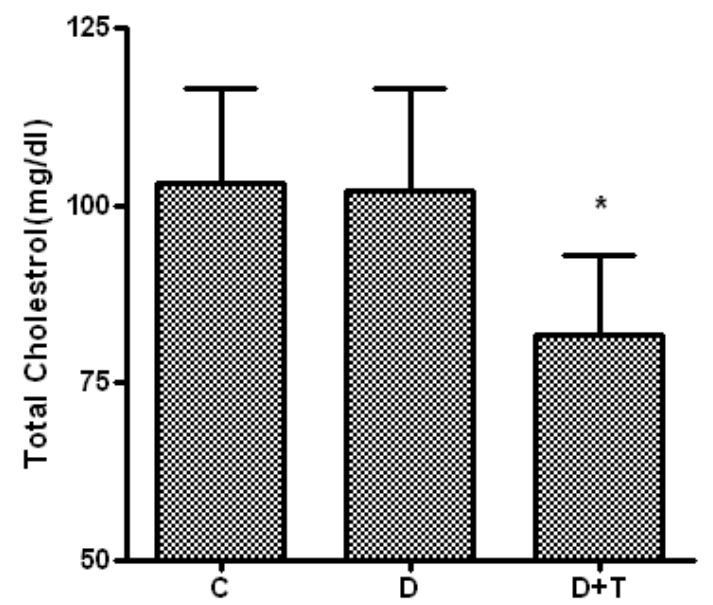

Fig. 3. Comparison of total cholesterol among control group, sea tangle supplemented group, and training and sea tangle powder supplemented group. C: control group, D: Sea Tangle powder supplemented group, D+T: Training and Sea Tangle Powder supplemented group, * significantly different with C and D.

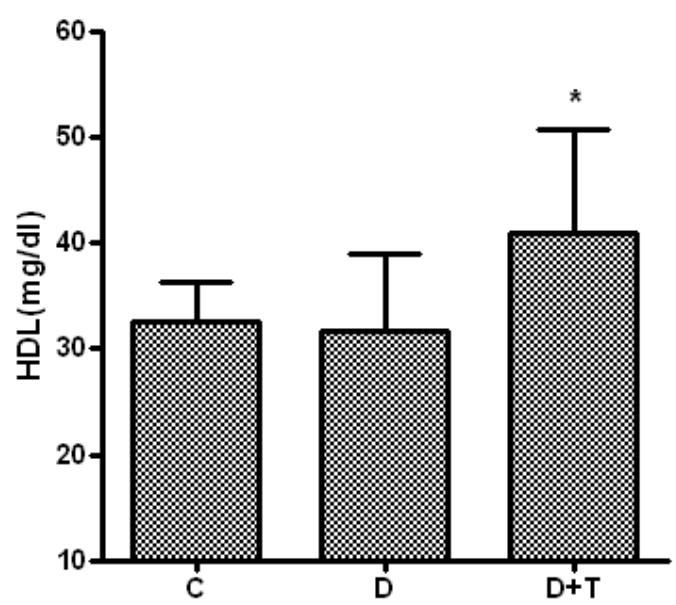

Fig. 4. Comparison of HDL-C among control group, sea tangle supplemented group, and training and sea tangle powder supplemented group. C: control group, D: Sea Tangle powder supplemented group, D+T: Training and Sea Tangle Powder supplemented group, * significantly different with $\mathrm{C}$ and $\mathrm{D}$.

않았다. TC는 다시마와 운동을 병행한 그룹이 대조군과 다시 마 투여그룹에 비해 낮은 수치를 보였으며, HDL-C는 다시마 와 운동을 병행한 그룹에서 다른 두 그룹과 비교하여 높은 수치를 보였다. LDL-C는 다시마군과 다시마와 운동 병행그룹 에서 대조군에 비해 낮은 수치를 보였다.

식이섬유는 혈당의 조절에 매우 중요한 역할을 하며, 이와 관련하여 수용성 식이섬유의 섭취가 효과적이다. 수용성 식이 섬유는 불용성 식이섬유에 비해 보수력이 커서 점도가 높은 겔(gel)을 형성하므로 위 내용물의 체류시간을 연장하고 흡수 


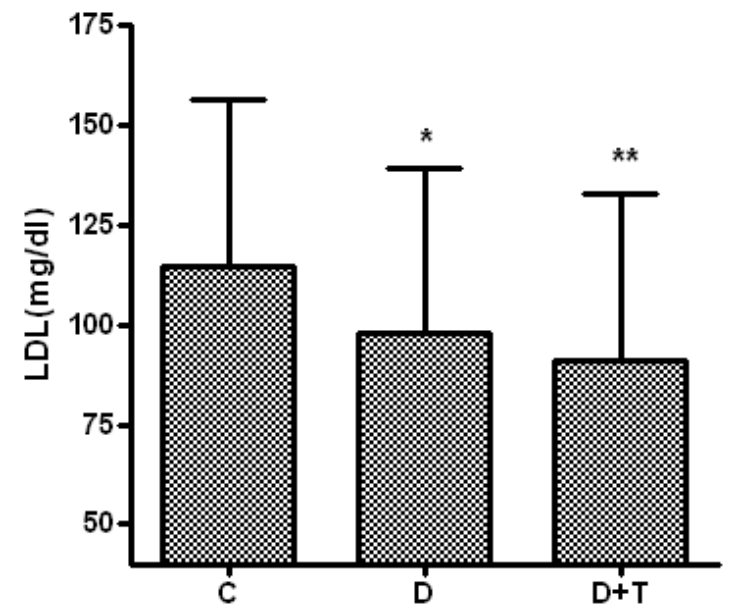

Fig. 5. Comparison of LDL-C among control group, sea tangle supplemented group, and training and sea tangle powder supplemented group. C: control group, D: Sea Tangle powder supplemented group, D+T: Training and Sea Tangle Powder supplemented group, * significantly different with $\mathrm{C}$, ** significantly different with $\mathrm{C}$ and $\mathrm{D}$.

억제 작용을 함으로써 포도당의 흡수를 저하시키고 소장에서 unstirred water layer를 증가시킴으로써 혈당 상승을 지연시 킨다고 Bennett과 Cerda [4]의 연구에서 보고하고 있다. 또한 Torsdottir 등[29]은 수용성 식이섬유의 일종인 algae로부터 추 출한 alginate 섬유소가 점성의 겔을 형성하여 위 배출시간을 지연시킴으로써 혈당을 개선시켰다고 보고하였다. 이와 관련 하여 Lee 등[19]의 연구에서는 당뇨 유발쥐들에게 다시마의 투여가 혈당 감소에 효과가 있는 것으로 보고하고 있다. 그러 나 정상군들에서는 혈당이 감소되는 경향은 있으나 유의한 차이는 없는 것으로 보고하고 있다. 이는 본 연구결과와 일치 하는 결과로서 혈당치가 정상인 그룹에서는 식이섬유가 혈당 에 미치는 영향이 미비하다 할 수 있을 것이다.

식이섬유의 섭취가 TC에 미치는 효과에 관한 기전은 상당 한 관심을 받아 왔으며 논쟁의 대상이 되어왔다. 1954년 Walker와 Arvidsson이 식이섬유(펙틴)가 TC에 미치는 효과 에 대해 반복적으로 연구하여온 이후로 Key 등[15]과 Jenkins 등[14]은 3주 이상 매일 $15-30 \mathrm{~g}$ 의 식이섬유가 함유된 식이를 피험자에게 섭취시킨 결과 $\mathrm{TC}$ 가 약 $13 \%$ 감소하였다고 제시하 였다. Goel 등[11]은 고콜레스테롤 식이와 함께 식이섬유를 섭취시킨 결과 혈장 $\mathrm{TC}$ 와 $\mathrm{TG}$ 를 감소시킨 것으로 나타난 반면 HDL-C의 수준에는 영향을 미치지 않는 것으로 보고하고 있 다. Madar 등[21]과 Fernandez 등[10]은 비만인 쥐에게 식이섬 유를 투여한 결과 LDL이 $33 \%$ 감소되었다고 보고하고 있다. Cho와 Bang [7]의 연구에서는 다시마의 투여가 TC, TG, HDL-C와 LDL-C에 긍정적인 영향을 미치는 것으로 보고하였 다. 식이섬유 중 비수용성 섬유는 소화과정 동안 본질적으로 변하지 않는 반면, 수용성 섬유는 젤과 같은 물질을 형성하기
위해 위 장관에서 수화되고 결장의 박테리아에 의해 발효되며 혈중 HDL-C량의 감소 없이 혈중 TC 및 LDL-C량 증가를 억제 하는 효과가 크다고 보고하고 있다[11]. 그러나 본 연구에서는 다시마투여 그룹에서 LDL-C의 감소효과만이 나타났다. 이러 한 결과는 식이섬유의 투여양의 차이, 그룹의 개체수에 따른 통계결과 등 연구방법의 차이에 기인한다고 할 수 있을 것이다.

규칙적인 운동은 TC, TG와 LDL-C를 감소시키고 HDL-C를 증가시킨다고 하였으며, 신체의 생리적, 생화학적 변화를 초 래하여 에너지 생산능력과 신체활동 능력을 향상시킬 뿐만 아니라 관상동맥질환을 예방하는 중요한 요인이 된다고 하였 다[1]. TC는 체내의 모든 세포에서 존재하며, 콜레스테롤 항상 성을 유지 도와주는데, $\mathrm{TC}$ 의 농도는 포화지방산이나 콜레스 테롤 섭취량이 증가하면 그 농도가 증가하며, 특히 단당류나 이당류의 섭취는 TC의 농도를 상승시키는 요인이 된다[16].

운동 형태와 강도에 따라 혈중 $\mathrm{TC}$ 은 운동시간이 길고 운동 강도가 높을수록 낮아지는 것으로 보고되고 있다[25]. 규칙적 인 운동에 의해 HDL-C 농도가 증가하는 것으로 알려져 있는 데[16], 이는 운동에 의해 혈장 내 LPLA가 활성화 되어 chylomicron, VLDL 및 LDL 내의 콜레스테롤이 HDL로 전환되는 비율이 증가되고 간의 HTGLA가 운동에 의해 통제됨으로서 $\mathrm{HDL}$ 의 catabolism이 낮아지기 때문이라고 하였다[12]. TG는 음식물에 의해 가장 많은 영향을 받지만, 신체적 훈련에 의해 서도 20-60\%까지 감소되어진다. 이는 운동으로 간 및 근육의 글리코겐이 소비되면서 근육과 순환되는 혈액 중의 지방이 에너지원으로 이용되기 때문이다[27]. 운동의 혈중 지질 개선 효과와 관련하여 운동 트레이닝과 관련된 연구들을 분석한 메타분석에 의하면 운동을 통해 HDL-C가 $4.6 \%$ 정도 증가되 고, TG와 LDL-C가 $3.7 \%, 5 \%$ 정도 감소되는 것으로 보고하고 있다[28].

본 연구에서는 비록 혈당과 $\mathrm{TG}$ 에 영향을 미치지 못하는 것으로 나타났지만, 다시마투여와 운동을 병행하였을 때 다시 마만을 투여 하였을 때 보다 TC, HDL-C, LDL-C에 긍정적인 효과가 있는 것으로 나타났다. 따라서 정상인들에게는 식이섬 유만을 섭취 하였을 때 혈중지질에 미치는 효과가 미비한 반 면 운동과 식이섬유의 섭취를 병행하였을 때 혈중지질에 미치 는 영향은 크다고 사료된다. 또한 후속연구로써 정상인들에게 운동이 혈중지질에 미치는 효과와 운동과 식이섬유의 섭취를 병행하였을 때의 비교를 통해 시너지효과에 대한 보다 명확한 규명이 이루어져야 할 것이다.

\section{감사의 글}

이 연구는 지식경제부 · 부산광역시 지원 지역혁신센터사 업(RIC08-06-07) 동의대학교 블루바이오 소재 개발 및 실용화 지원 센터의 지원으로 이루어졌습니다. 


\section{References}

1. Ahn, Y. J. 1998. Effect of caloric restriction and training regimens on body composition, serum lipids, and muscle strength. PhD Dissertation. Korea National Sport University.

2. Andersen, R. E., T. A. Wadden, S. T. Bartlett, R. A. Vogt, and R. S. Weinstock. 1995. Relations or weight loss to changes in serum lipids and lipoproteins in obese women. American Journal of Clinical Nutrition 62, 350-357.

3. Anderson, J. W. and W. J. L. Chen. 1979. Plant fiber, Carbohydrate and lipid metabolism. Am J. Clin. Nutr. 32, 346-363.

4. Bennett, W. G. and J. J. Cerda. 1996. Benefits of dietary fiber. Postgraduate Medicine 99, 153-156.

5. Camerson-Smith, D., R. Habito, M. Barnett, and G. R. Collier. 1997. Dietary guar gum improves insulin sensitivity in streptozotocin-induced diabetic rats. J. Nutr. 127, 359-364.

6. Chen, M .S., C. S. Kao, and C. J Chang. 1991. Prevalence and risk factors of diabetic retinopathy among non-insulin-dependent diabetic subjects. Am J. Ophthalmol 114, 723-730.

7. Cho, Y. J. and M. A. Bang. 2004. Effects of dietary sea tangle on blood glucose, lipid an d glutathione enzymes in streptozotocin-induced dibetic rats. Korean J. Food Culture 19, 419-428.

8. Colliec, S., A. M. Fischer, J. Tapon-Bretaudiene, C. Boisson, P. Durand, and J. Jozefonvcz. 1991. Anticoagulant properties of a fucoidan fraction. Thromb Res. 64, 143-154.

9. Deshiaies, Y., F. Begin, L. Savoie, and C. Vachon. 1990. Attenuation of the meal-induced increase in plasma lipids and adipose tissue lipoprotein lipase by guar gum in rats. Journal of Nutrition 120, 64-70.

10. Fernandez, M. Z., A. Trejo, and D. J. McNamara. 1990. Pectin isolated from prickly pear modifies low density lipoprotein metabolism in cholesterol-fed guniea pigs. Journal of Nutrition 120, 1280-1290.

11. Goel, B., B. Ooraikul, and T. K. Basu. 1997. Cholesterol lowering effect of rhubarb stalk fiber in hypercholesterolemic men. J. Am Col. Nutr. 19, 600-604.

12. Goldberg, L., D. L. Elliot, R. W. Schultz, and F. E. Kloster. 1984. Changers in lipid and liporotein levels after weight training. Journal of the American Medical Association 252, 504-506.

13. Jenkins, D. J. A., A. R. Leeds, A. R. Gassull, B. Coche, and G. M. A. Alberti. 1977. Decrease in postrpriandial insulin and glucose concentration by guar and pectin. Ann. Intern. Med 86, 20-23.

14. Jenkins, D. J. A., T. M. S. Wolever, R. H. Taylor, D. Reynolds, R. Nineham, and T. D. R. Hockaday. 1980. Diabetic glucose control, lipids and trace elements on long term guar. Birt. Med J. 280, 1353-1354.

15. Keys, A. and A. S. Trusswell. 1977. Effect of citrus pectin on blood lipid and fecal sterol excretion in man. American
Journal of Clinical Nutrition 30, 171-175.

16. Kim, B. R. and J. P. Park. 2003. The effects of bare foot feet walking on the body composition and blood lipid profiles of obese female-studnets in the middle school. The Korean Journal of Physical Education 12, 517-528.

17. Kim, M. K. and J. E. Paek. 1997. Effect of dietary fibers in rice and barley on lipid and cadmium metabolism in the rat. Korean J. Nutr. 30, 252-265.

18. Kodama, S., M. Shu, K. Saito, H. Murakami, K. Tanaka, S. Kuno. R. Ajisaka, Y. Sone, F. Onitake, A. Takahashi, H. Shimano, K. Kondo, N. Yamada, and H. Sone. 2007. Even low-intensity and low-volume exercise training may improve insulin resistance in the elderly. Internal Medicine 46, 1071-1077.

19. Lee, K. S., B. S. Bae, M. J. Bae, M. A. Jang, J. S. Seo, and Y. S. Choi. 1999. Effect of sea tangle and metformin on lipid peroxide and antioxidants levels in diabetic rats. J. Korean Nutrition Society 32, 230-238.

20. Lee, K. S., J. S. Seo, and Y. S. Choi. 1998. Effect of sea tangle and hypoglycemic agent on lipid metabolism in diabetic rats. J. Korean Soc. Food Sci. Nutr. 27, 960-967.

21. Madar, Z. and R. Throne. 1987. Dietary fiber. Progress in Food and Nutrition Science 11, 153-174.

22. Newman, R. K., C. W. Newman, and H. Graham. 1989. The hypocholesterolemic function of barley $\beta$-glucans. Cereal Foods World 34, 883-886.

23. Nishimune, T. T. Sumimoto, T. Yakusiji, and N. Kunita. 1991. Determination of total dietary fiber in Japaneses foods. J. Assoc. Off. Anal. Chem 74, 350-359.

24. Nishina, P. M., B. O. Schneeman, and R. A. Freedland. 1991. Effects of dietary fibers on non fasting plasma lipopotein and apolipoprotein levels in rats. J. Nutr. 121, 431-437.

25. Park, J. Y., M. J. Kim, Y. K. Kim, Y. S. Jin, and H. J. Lee. 1999. The effect of exercise pattern and antioxidant supplement on antioxidant enzymes and total antioxidant status. The Korean Journal of Physical Eduation 38, 451-460.

26. Riccardi, G. and A. A. Rivelles. 1991. Effects of and dietary fiber and carbohydrates on glucose and lipoprotein metabolism in diabetic patients. Diabets 14, 1115-1125.

27. Scjokman, C. P., H. Ingrid, E. Rutishauser, and R. J. Wallace. 1999. Pre and post game macronutritient intake of a group of elite Australian football players. Int. J. Sport Nutr. Exerc. Metab. 9, 60-96.

28. Thompson, P. D., D. Buchner, I. L. Pina, G. J. Balady, M. A. Williams, B. H. Marcus, K. Berra, S. N. Blair, and F. Costa. 2003. Exercise and physical activity in the prevention and treatment of aterosclerotic cardiovascular disease. Circulation 107, 3109-3116.

29. Torsdottir, J., M. Alpsten, G. Holm, A. S. Sandberg, and J. Tolli. 1991. A small dose of soluble alginate-fiber affects postprandial glycemia and gastric emptying in humans with diebetes. J. Nutr. 121, 795-799.

30. Trowell, H. 1978. Diabetes mellitus and dietary fiber of starchy foods. Am J. Clin. Nutr. 31, S53-S57. 
초록 : 다시마 보충과 운동훈련이 흰쥐의 혈당과 혈중지질에 미치는 영향

황혜진 ${ }^{1} \cdot$ 곽이섭 ${ }^{2} \cdot$ 김향숙 ${ }^{1} \cdot$ 최영현 ${ }^{3} \cdot$ 김병우 ${ }^{4} \cdot$ 권현주 $^{4} \cdot$ 윤병곤 $^{5}$ *

$\left({ }^{1}\right.$ 동의대학교 식품영양학과, ${ }^{2}$ 동의대학교 체육학과, ${ }^{3}$ 동의대학교 한의학과, ${ }^{4}$ 동의대학교 생명응용공학과, 5동의대학교 특수체육학과)

본 연구의 목적은 다시마투여와 운동트레이닝이 흰쥐의 혈당과 지질성분에 미치는 영향을 규명하기 위함이다. 4 주령의 수켯 쥐 27 마리를 대조군 $(\mathrm{C}, \mathrm{n}=9)$, 다시마투여군 $(\mathrm{D}, \mathrm{n}=9)$ 과 다시마투여와 운동트레이닝군 $(\mathrm{D}+\mathrm{T}, \mathrm{n}=9)$ 으 로 나누었다. 운동트레이닝은 6주간 1주일에 5회, 30분간 트레드밀위에서 실시하였다. 혈당(C:175.9 47.5 , $\mathrm{D}: 173.9 \pm 34.0, \mathrm{D}+\mathrm{T}: 165.0 \pm 38.0 \mathrm{mg} / \mathrm{dl})$ 과 중성지질 $(\mathrm{C}: 251.1 \pm 91.8, \mathrm{D}: 215.0 \pm 90.0, \mathrm{D}+\mathrm{T}: 200.0 \pm 89.3)$ 의 집단 간의 차이 는 존재하지 않았다. 콜레스테롤수치는 $\mathrm{D}+\mathrm{T}$ 군 $(81.8 \pm 11.2)$ 이 다른 두집단에 비해 낮았다(C:103.0 $\pm 13.5, \mathrm{D}: 102.1 \pm$

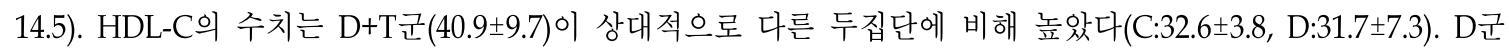

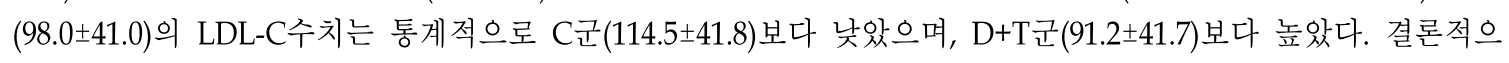
로, 다시마투여와 운동트레이닝은 혈중지질에 긍정적인 효과를 가져왔다. 